\section{JULIETTE JOINS IMPLANTOLOGY COMMITTEE}

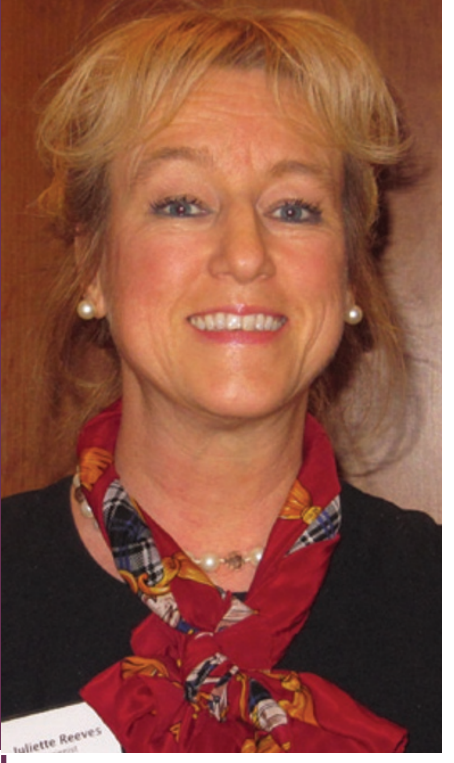

Dental hygienist Juliette Reeves is the first dental care professional (DCP) to be elected onto the committee of the Association of Dental Implantology (ADI).

The ADI Committee meets on a quarterly basis to direct the future of the organisation on behalf of its 2,000 members. Juliette will be involved in liaising with and representing the ADI's DCP members, ensuring that their interests are being met.

Juliette said: 'I am delighted to have been given the opportunity to work with the ADI Committee on behalf of my fellow DCPs. As the field of implant dentistry develops and the number of implant placements increases, it is critical that the dental team also progresses.'

Juliette is a dental hygienist and nutritionist with over 30 years' experience. Her main areas of interest are nutritional influences in periodontal disease, stress and bone density. She has received training in implant maintenance from master class academies in Geneva, Liechtenstein and more recently in the US

DCP membership of the ADI has increased over the past two years by $750 \%$. This year the association will be providing implant training in the form of Original and Advanced Dental I Nurses' Courses and introducing a brand new course for hygienists and therapists.

\section{MAPLE DENTAL CARE CROWNED PRACTICE OF THE YEAR}

Maple Dental Care Ltd were awarded British Dental Association (BDA) Good Practice Scheme Practice of the Year 2012 at the seventh annual BDA Honours and Awards Dinner held on 21 November at the Plaisterers' Hall, London.

Maple Dental Care Ltd is a mixed NHS and private dental practice founded in 1954 in Brooklands, Manchester with five dentists, four dental therapists, two oral health educators and a highly skilled support team, and is also an approved NHS training practice for newly qualified dentists.

The Maple Dental Care dental team receiving their Good Practice award

\section{INNOVATION AWARD FOR BRUSHING APP}

Dentist Ben

Underwood's Brush DJ app for smartphones has won a Best Dental Innovation award. The app is designed to

make toothbrushing

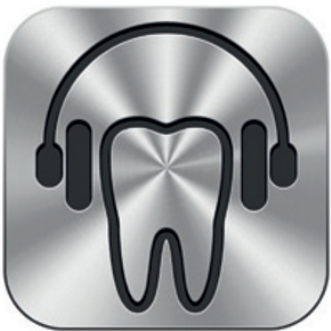

fun and effective. It has been downloaded in 149 countries.

Ben, from York, said: 'Winning the award has been a great honour and made all the work that has gone into the development of Brush DJ worthwhile'

In conjunction with the app, the first series of animations showing how to carry out basic oral hygiene tasks has been uploaded to YouTube and another five were set to be uploaded as Vital goes to press. www.youtube.com/watch? $v=w X F g T P s Q S 8 Y$
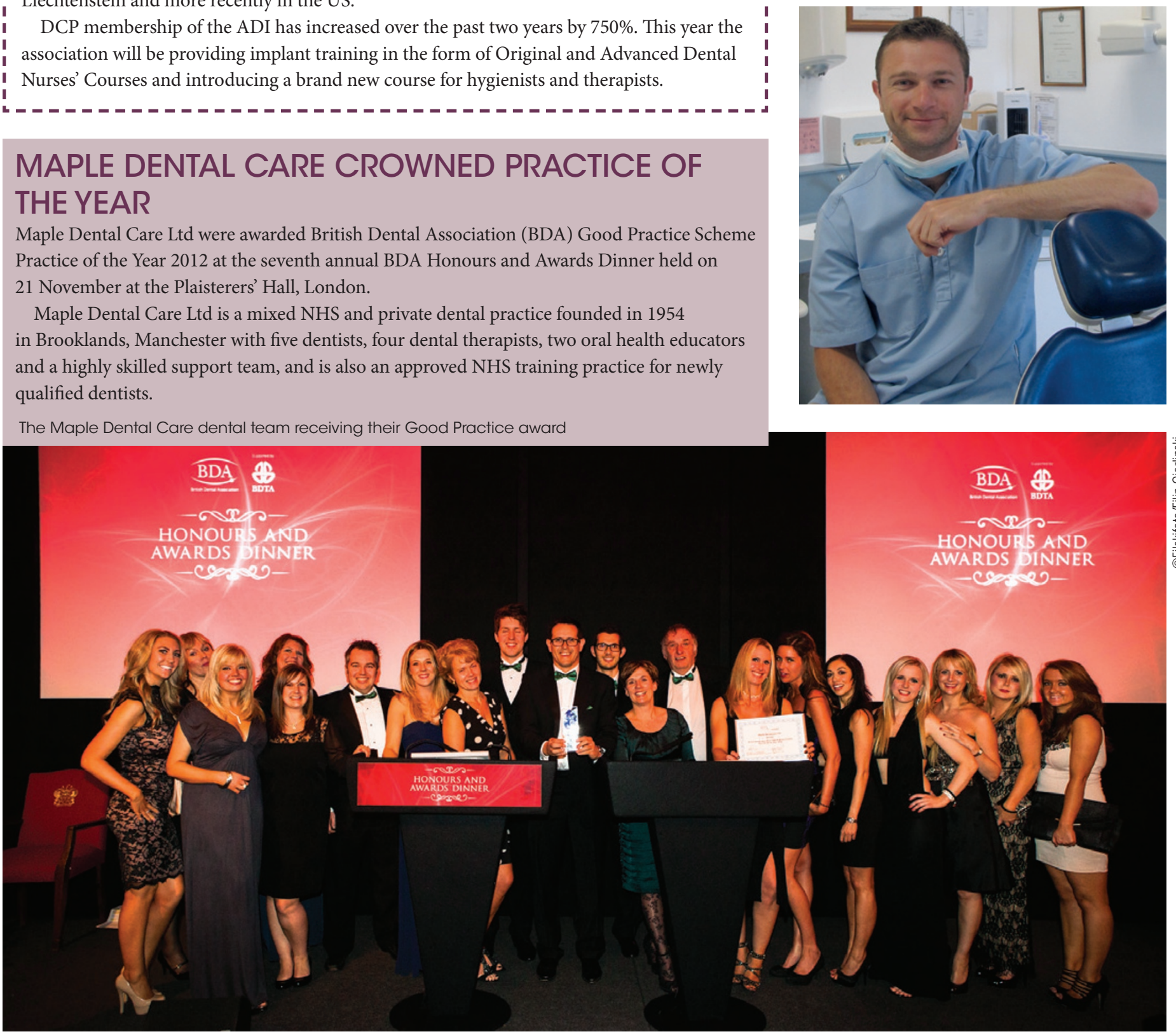